\title{
How Recipes of National Cultural Values, Wealth, Economic Inequality, and Religiosity Explain Consumer Tipping Behavior: An Abstract
}

\author{
Graham Ferguson, Carol M. Megehee, and Arch G. Woodside
}

\begin{abstract}
This chapter proposes a holistic (i.e., "recipe" or "algorithm") postpositivistic approach to theory and data analysis to learn the impacts of alternative cultural complex wholes on the proportion of service professions within a nation. The study here includes substantially re-examining and extending the theory and findings by Lynn et al. (1993) to better explain tipping behavior and to show that, depending on the other ingredients in a recipe, each cultural attribute can work in different ways to explain tipping frequency. The findings offer a deeper, richer, perspective of how cultures affect consumer behavior than conventional positivistic tests. While voluntary tipping is becoming more common around the world, the antecedents of tipping behavior are ambiguous in the existing literature and do not provide a clear mechanism for researchers or policy makers to understand tipping expectations and behavior nor how to influence them. Partly, this ambiguity is caused by studies that deconstruct the ingredients of culture and report on the symmetric "net effect" of each ingredient (i.e., each specific capability and habit) rather than investigating culture as a "complex whole" (Tylor 1871/1920).
\end{abstract}

\footnotetext{
G. Ferguson $(\bowtie)$

Curtin University, Bentley, WA, Australia

e-mail: g.ferguson@curtin.edu.au

C.M. Megehee

Coastal Carolina University, Conway, SC, USA

e-mail: cmegehee@coastal.edu
}

A.G. Woodside

Boston College, Chestnut Hill, MA, USA

e-mail: arch.woodside@bc.edu 